\title{
Analysis of the Parameters of Lactulose Drying in Terms of Yield and Quality of the Finished Product
}

\author{
Vyacheslav Fedorovich Dolganyuk, Boris Gavrilovich Gavrilov, \\ Olga Olegovna Babich, Lyubov Sergeevna Dushlyuk and \\ Svetlana Yurevna Noskova
}

\begin{abstract}
Federal State-owned Budgetary Educational Institution of Higher Education "Kemerovo Institute of Food Science and Technology (University)".
\end{abstract}

DOI: http://dx.doi.org/10.13005/bbra/1908

(Received: 06 August 2015; accepted: 19 September 2015)

\begin{abstract}
The dependence of the parameters of quality and yield of the finished product on the basic parameters of drying was studied. Such quality parameters as particle size, moisture content, and how they are affected by the drying temperature, the feed rate of the liquid in the chamber and air flow rate were considered. It is shown that the optimum drying temperature that allows to get the highest yield with a mass fraction of moisture not exceeding normalizable is $140-160^{\circ} \mathrm{C}$. The feed rate of the solution that provides the maximum yield having the required humidity and the optimum particle size is $5-7 \mathrm{ml} /$ min. The optimal values were also defined for the air flow rate at which the yield of the final product is the highest and the mass fraction of moisture in it is the lowest, which lie in the range of $15-25 \mathrm{~m}^{3} / \mathrm{h}$. After determining the optimum parameters providing the highest yield of lactulose powder having the desired levels of quality, the studies of the organoleptic and physicochemical parameters have been conducted, as well as an analysis of the content of the toxic elements in the resulting product. The results of the analysis allow to conclude that the values of the investigated parameters in the obtained lactulose powder do not exceed the normalized values and the product in general meets the requirements set by the regulatory documentation.
\end{abstract}

Keywords: Lactulose, prebiotic, spray drying, hygroscopicity, temperature, particle size

Due to the increasing popularity of lactulose consumption, the development of new improved technology of its production, search for optimal parameters that allow to increase the yield of the final product, as well as optimization of existing technologies are currently the actual and perspective scientific area ${ }^{4,5}$.

Lactulose is one of the most promising carbohydrate prebiotics thanks to numerous bifidogenic properties proven and studied by a number of domestic and foreign institutions ${ }^{1,2,6}$.

* To whom all correspondence should be addressed.
Only using lactulose in the composition of a variety of functional foods allowed to reach a considerable success and results, including systematization, updating and significant progress in the field of physicochemical and technological patterns of methods to produce this prebiotic. As a result, the solution of complex problems of technology of producing dry lactulose became possible and necessary in modern conditions ${ }^{10,14}$. Objects and methods of research

Experimental studies were performed in the laboratory of the Research Institute of Biotechnology of the Federal State-owned Budgetary Educational Institution of Higher Education "Kemerovo Institute of Food Science and Technology (University)". 
The object of the study was a solution with a mass fraction of $50 \%$ lactulose provided by LLC "Shekhon-L" (Yaroslavl, Russia).

Samples were dried in the Mini Spray Dryer (Buchi, Sweden), which allowed to obtain a finished product with a particle size of 1-25 microns. Mass fraction of solids in solutions of lactulose was determined refractometrically according to GOST 24908-84.

The weight proportion of lactulose and other carbohydrates in solution and dry lactulose was determined using the gas-liquid chromatography (GLC) method with a GCMSQP2010 Ultra (Shimadzu, Japan) chromatograph.

Organoleptic indicators of the test samples were determined as follows:

a) Appearance and consistency: the overall visual impression of the product was characterized (the nature of the surface, uniformity, shape);

b) Color: the color of the developed product was determined, as well as deviations from the color;

c) Smell: it was determined whether the aroma was typical for this type of product.

d) Taste: it was determined whether the taste was typical for this type of product.

The particle size was determined by microscopy of the lactulose sample on the inverted microscope-AxioVert.A1 (Carl Zeiss AG, German) with $\times 40$ zoom.

Determination of content of toxic elements, pesticides, antibiotics and radionuclides:

Lead - according to GOST R 51301 "Food raw materials and products. Stripping voltammetry methods for determining the content of toxic elements (cadmium, lead, copper and zinc)", GOST 26932 "Food raw materials and products. Methods for determination of lead", GOST 30178 "Food raw materials and products. Atomic absorption method for determination of toxic elements", GOST 30538 "Food products. Method of determination of toxic elements by atomic emission method" and MG 4.1.986 "Methods of measurement of the mass fraction of lead and cadmium in food products and food raw material by electrothermal atomic absorption spectrometry. Methodic guidelines";

Arsenic - according to GOST R 51766 "Food raw materials and products. Atomic absorption method for determination of arsenic";
- cadmium - according to GOST R 51301 "Food raw materials and products. Stripping voltammetry methods for determining the content of toxic elements (cadmium, lead, copper and zinc)", GOST 26932 "Food raw materials and products. Methods for determination of cadmium", GOST 30178 "Food raw materials and products. Atomic absorption method for determination of toxic elements", GOST 30538 "Food products. Method of determination of toxic elements by atomic emission method" and MG 4.1.986 "Methods of measurement of the mass fraction of lead and cadmium in food products and food raw material by electrothermal atomic absorption spectrometry. Methodic guidelines";

Mercury - according to GOST 26927

"Food raw materials and products. Methods for determination of mercury" and MG 5178 "Methodic guidelines for the determination of mercury in food products".

Mass fraction of moisture was determined on the Chizhova device.

\section{RESULTSAND DISCUSSION}

By analyzing data on the factors responsible for the drying process, a comprehensive chart of optimum parameters was built for a solution with a mass fraction of $50 \%$ lactulose (Figures 1, 2, 3). In setting the drying temperature, the yield and the mass fraction of moisture in the product were considered.

Based on the data shown in Figure 1, the yield of the finished product was set the highest at the drying temperature of $140-160^{\circ} \mathrm{C}$, and the mass fraction of moisture meets requirements at 120 $160^{\circ} \mathrm{C}$. Therefore, the optimal values of the temperature are $140-160^{\circ} \mathrm{C}$.

To determine the optimum values of the feed rate of the solution, parameters such as humidity, particle size and yield of the final product were considered (Figure 2). The optimum value of feed rate is $5-7 \mathrm{ml} / \mathrm{min}$.

The optimum values of the air flow rate are given in Figure 3. It was found that the optimal range of values of air flow rate at which the yield of the final product is the highest and the mass fraction of the moisture therein is the lowest is 15 $25 \mathrm{~m}^{3} /$ hour.

Lactulose is a highly hydrophilic substance capable of exchanging moisture with 
the environment. It has energetically unsaturated areas called active sorption sites and capable of binding one or more molecules of water. This substance actively reacts with water in any environment interface. The very structural form of the water molecule defines its high reactivity through hydrogen bond formation. The hydrogen bond is characterized by high mobility, so even

Table 1. Organoleptic indicators of lactulose powders

\begin{tabular}{ll}
\hline Indicator & Characteristics \\
\hline Appearance and consistency & Homogeneous fine powder. \\
Taste and smell & Sweet and clear, without foreign tastes and odors \\
Color & White, with a faint yellow tint. \\
\hline
\end{tabular}

Table 2. Content of toxic elements in dry lactulose

\begin{tabular}{lcc}
\hline Indicator & Permitted value & Actual value \\
\hline Lead, $\mathrm{mg} / \mathrm{kg}$, at most & 0.5 & $0.10 \pm 0.001$ \\
Arsenic, $\mathrm{mg} / \mathrm{kg}$, at most & 0.5 & $0.20 \pm 0.001$ \\
Cadmium, $\mathrm{mg} / \mathrm{kg}$, at most & 0.1 & $0.04 \pm 0.001$ \\
Mercury, $\mathrm{mg} / \mathrm{kg}$, at most & 0.02 & $0.01 \pm 0.001$ \\
Pesticides & & \\
Hexachlorocyclohexane, at most & 0.5 & Not found \\
DDT and its metabolites, at most & 0.05 & Not found \\
Radionuclides & & \\
Cesium-137 Bq/kg, at most & 400 & Not found \\
Strontium-90 Bq/kg, at most & 100 & Not found \\
\hline
\end{tabular}

Table 3. Physicochemical indicators of dry lactulose

\begin{tabular}{lll}
\hline Indicator & Standard & Actual value \\
\hline Mass fraction of lactulose, \%, at least & $75.2 \pm 0.2$ & $75.2 \pm 0.2$ \\
Mass fraction of the rest of carbohydrates, \%, at least: & $25.0 \pm 0.2$ & $24.8 \pm 0.1$ \\
- lactose: & & $13.1 \pm 0.1$ \\
- $\alpha$-lactose; & & $7.8 \pm 0.1$ \\
- $\beta$-lactose; & & $5.3 \pm 0.1$ \\
- galactose & & $11.7 \pm 0.1$ \\
\hline
\end{tabular}

with a slight change in the parameters of the interaction of the substance with water, noticeable transformations of its properties occur. In other words, a change in temperature, atmospheric moisture saturation or pressure cause response changes in the structure and properties of the objects of storage or processing ${ }^{7,8,9}$.

The hydrophilicity of the product over time leads to a loss of organoleptic properties, causes worsening of solubility and inability of correct dosing of the substance, which is an important parameter for prebiotics use in a healthy $\operatorname{diet}^{3,12,13}$.
Also, moisture stimulates the development of microbiological processes, which results in accumulation of degradation products of sugars; the $\mathrm{pH}$ is reduced and an inversion occurs. This leads to loss of active properties of lactulose, and in the worst cases, the various types of spoilage can adversely affect the health of the consumer ${ }^{11,15}$.

In connection with the above, a study on the hygroscopicity of lactulose using desiccator was conducted. The results show that the concentration of lactulose and hygroscopicity are inversely proportional to each other - the higher 
the concentration of the substance in the initial solution, the less hygroscopic it is.

For a more detailed study of the production process of dry lactulose from solution, the assessment of the organoleptic characteristics of the finished product was made. The results of the study of organoleptic characteristics of lactulose powder are presented in Table 1.

An organoleptic analysis (Table 1) shows that the finished product is a fine powder having high hygroscopicity. Taste and smell of the product are sweet and clear, without foreign tastes and odors. The powder color is from white to light yellow.

The next stage of research was to study the physicochemical characteristics of the lactulose powders. Physicochemical methods are characterized by high sensitivity and selectivity and require a small amount of sampling material. In many cases, there is no need to define the determined components in the sampling material, and the whole course of analysis sometimes takes only a few minutes. Therefore, physicochemical control allows to quickly collect the necessary

Table 5. Table of highs of the gas-liquid chromatogram of dry lactulose

\begin{tabular}{lccccc}
\hline No. & Name & Time & Height & Area & Concentration \\
\hline 1 & & 226 & 0.4 & 4.0 & 0.3 \\
2 & & 368 & 4.3 & 70.8 & 4.5 \\
3 & & 405 & 4.6 & 66.0 & 4.2 \\
4 & & 425 & 1.8 & 23.0 & 1.5 \\
5 & & 448 & 10.4 & 159.1 & 10.1 \\
6 & e- lactose & 1198 & 1.1 & 36.8 & 2.3 \\
7 & lactulose & 1401 & 18.6 & 1015.1 & 64.2 \\
8 & $\alpha$ - lactose & 1479 & 2.6 & 122.1 & 7.7 \\
9 & $\beta$ - lactose & 1844 & 1.5 & 85.4 & 5.4 \\
Sum & & & 45.2 & 1582.3 & 100.0 \\
\hline
\end{tabular}

Table 4. Table of highs of the gas-liquid chromatogram of a solution with a mass fraction of $50 \%$ lactulose

\begin{tabular}{lccccc}
\hline No. & Name & Time & Height & Area & Concentration \\
\hline 1 & & 360 & 3.5 & 56.3 & 2.9 \\
2 & & 375 & 2.8 & 46.6 & 2.4 \\
3 & & 415 & 7.7 & 117.6 & 6.0 \\
4 & & 435 & 4.2 & 58.8 & 3.0 \\
5 & & 457 & 13.4 & 214.6 & 10.9 \\
6 & e- lactose & 1221 & 1.4 & 52.2 & 2.6 \\
7 & lactulose & 1430 & 16.6 & 1126.7 & 57.2 \\
8 & $\alpha$ - lactose & 1514 & 3.3 & 164.8 & 8.4 \\
9 & $\beta$-lactose & 1899 & 2.0 & 6.8 & 6.8 \\
Sum & & & 54.7 & 1971.3 & 100.0 \\
\hline
\end{tabular}

information to evaluate the quality of various products. It enables to determine the level of purity, the presence and type of impurities.

Studies have been conducted on the content of toxic elements in the products after production. The data obtained is presented in Table 2.

The results indicate that the migration of toxic elements in the product is not noticed, controlled potentially hazardous chemicals are contained in the product in concentrations that do not exceed the established limits by times.

In accordance with GOST R 51074-2003, the shelf life is a period during which the food product in compliance with the storage conditions set retains the properties specified in the regulatory or technical documents. Its expiration does not mean that the product is not suitable for 
the intended use. In other words, during this period, the product completely retains the flavor, consistence, aroma and useful properties in the same way as at the production.

The active acidity is a measure of product quality. According to this indicator, you can judge the degree of degradation of sugars in the product.

The present study determined the change in active acidity of the lactulose solution under the influence of heat treatment. Dependence of the change in active acidity on the temperature of heating the sample dry lactulose is shown in Fig. 4.

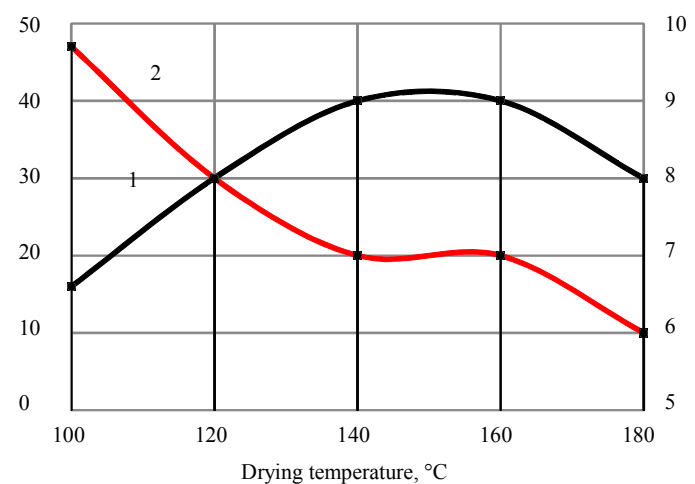

Fig. 1. Dependence of moisture content and product yield on the temperature of drying lactulose solutions with a mass fraction of $50 \%$ : 1-yield (\%); 2-moisture content (\%).

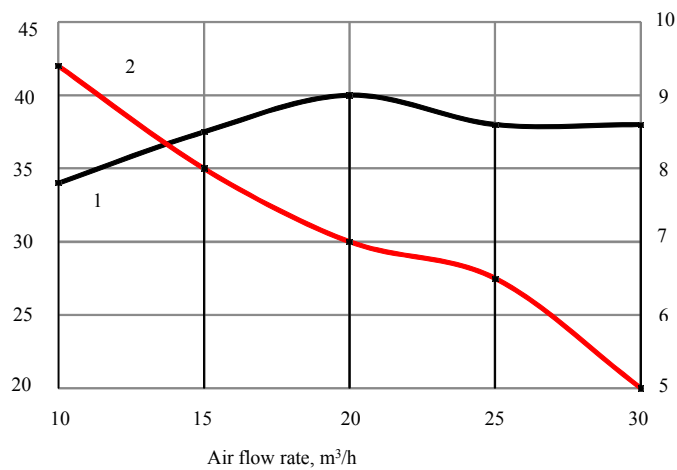

Fig. 3. Dependence of the basic parameters of dry lactulose on air flow rate $\left(\mathrm{m}^{3} / \mathrm{h}\right)$ for solutions with mass fraction of $50 \%$ lactulose: 1 - yield $(\%) ; 2$ - moisture content (\%).
The research results presented in Figure 4 show a decline in indicator of active acidity with increasing the processing temperature. The initial $\mathrm{pH}$ of the lactulose solution with a mass fraction of $50 \%$ equal to 4.7 is determined by the presence of organic acids in the initial solution, such as lactic acid and, to a lesser extent, acetic and formic acids. The maximum value of the acid indicator is observed in the non-heat-exposed sample, and it is equal to 4.7 . For a sample processed at $100^{\circ} \mathrm{C}$, the minimum value of the indicator of the acid acidity is observed, and it is equal to 3.75 . The

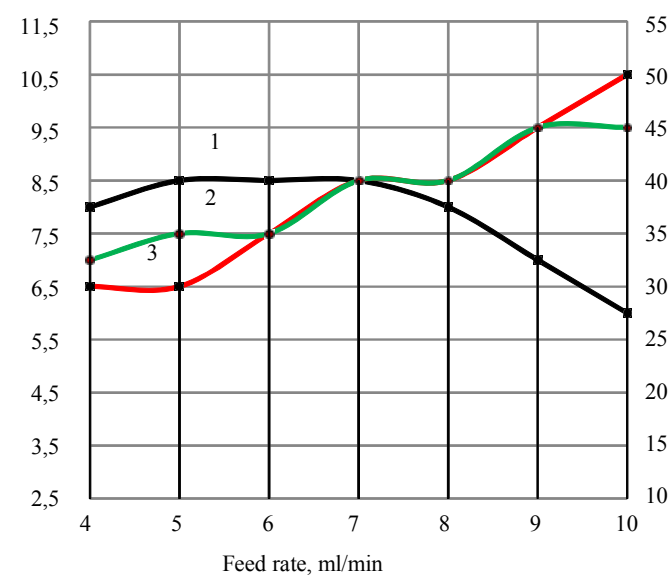

Fig. 2. Dependence of moisture content, yield and particle size on the feed rate of lactulose solution with a mass fraction of $50 \%$ : 1 - yield (\%); 2-moisture content (\%); 3 - particle size (microns)

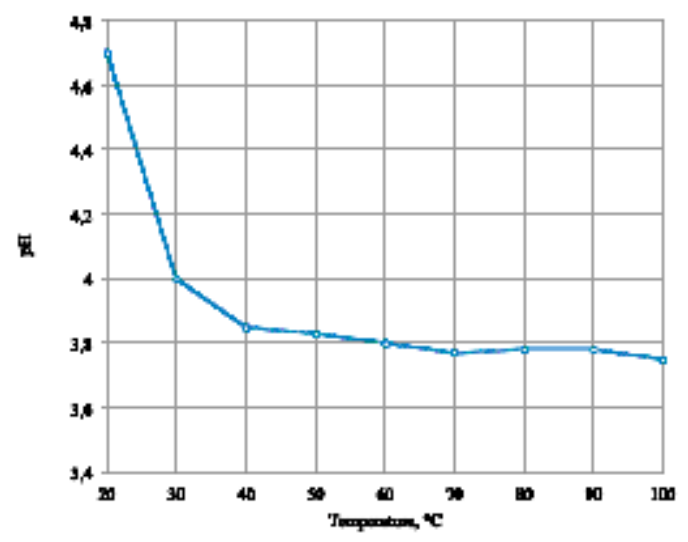

Fig. 4. Dependence of change in the $\mathrm{pH}$ of the lactulose solution on the sample heating temperature 
sharp change in active acidity from 4.7 to 3.82 begins at processing solution at temperatures from $20^{\circ} \mathrm{C}$ to $40^{\circ} \mathrm{C}$. Further there is a smoother decrease in acidity from 3.82 to 3.78 at temperatures from $40^{\circ} \mathrm{C}$ to $70^{\circ} \mathrm{C}$.

This fact is probably connected with the formation of products of destruction of lactulose and shifting $\mathrm{pH}$ to the acid side.

Results of the study of physicochemical indicators of dry lactulose are presented in Table 3.

According to the research, the mass fraction of lactulose in the final product was $75.2 \%$, which meets the standard of $75 \%$. Mass fraction of the rest of carbohydrates is $24.8 \%$, which is below the standard value equal to $25 \%$. The accompanying carbohydrates include lactose, which accounts for a mass fraction of $13.1 \%$. Lactose in the syrup is presented by á- and âisomers. Also present in the solution is galactose, mass fraction of which is $11.7 \%$ of the total weight of the carbohydrates in the sample.

In order to confirm the results of the study of qualitative indicators of dry lactulose, the chromatographic analysis of the obtained sample and the initial solution of lactulose was conducted (Figs. 5 and 6)

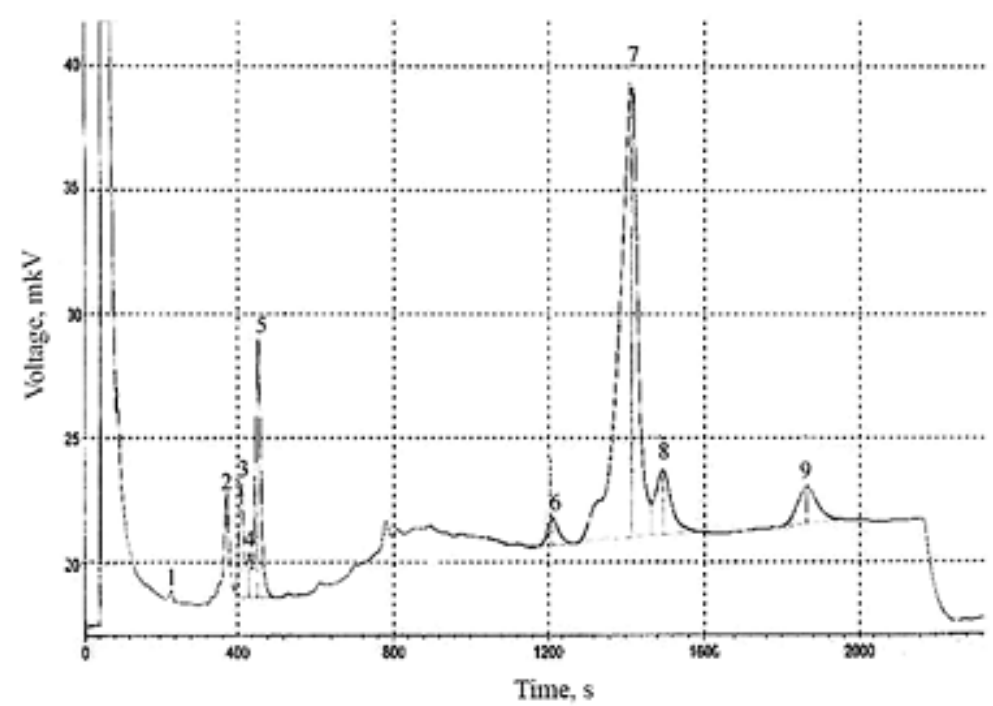

Fig. 5. Gas-liquid chromatogram of a solution with a mass fraction of $50 \%$ lactulose

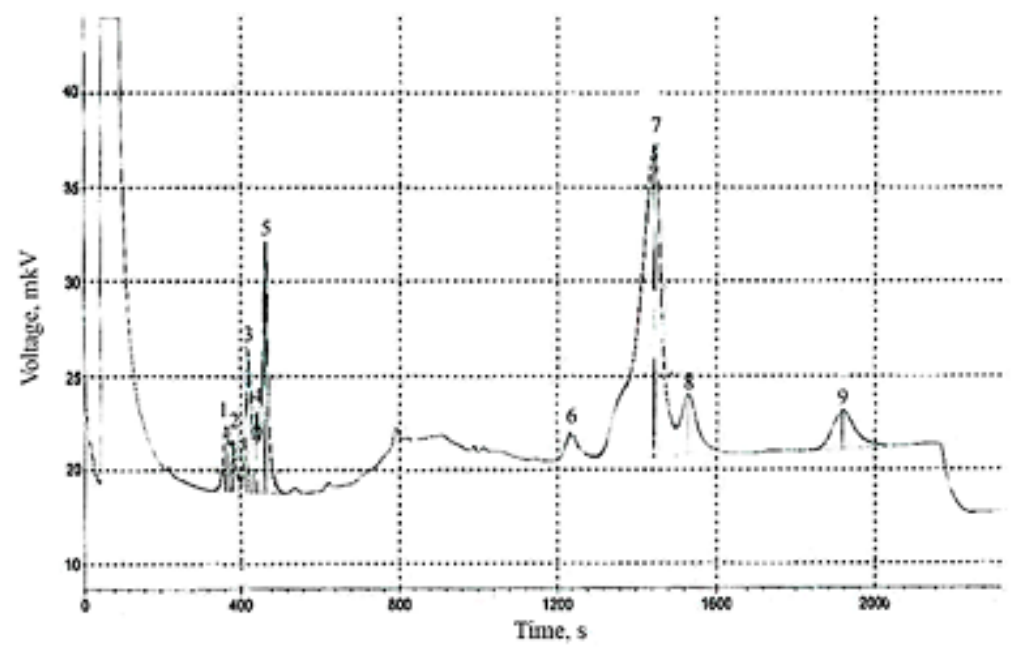

Fig. 6. Gas-liquid chromatogram of dry lactulose 
Availability and development of ways of determining carbohydrates is the method of gasliquid chromatography. It is based on a translation of saccharides into volatile trimethylsilyl derivatives followed by their separation on GCL column and determination by a flame ionization detector

As shown by the results of studies, the GLC method has high accuracy and resolution and allows to qualitatively and quantitatively determine lactulose in the presence of alpha and beta forms of lactose, galactose, glucose, tagatose, fructose and other carbohydrates.

The analysis of the chromatograms shown in Figures 5 and 6 allowed to find that the concentration of lactulose in the initial syrup is $50 \%$, in the dried product $-48.2 \%$. Thus, as a result of chemical reactions, lactulose loss after drying is $3.5 \%$, which does not exceed the permissible value by using spray drying.

Based on the physicochemical parameters of dry lactulose, we can say that the finished product meets the quality requirements for dry lactulose powders.

\section{CONCLUSION}

Thus, in the course of the study, it was found that the optimum drying temperature that allows to obtain the highest yield with a mass fraction of water not exceeding normalizable is 140$160^{\circ} \mathrm{C}$. The feed rate of the solution that provides the maximum yield having the required humidity and the optimum particle size is $5-7 \mathrm{ml} / \mathrm{min}$. The optimal values were also defined for the air flow rate at which the yield of the final product is the highest and the mass fraction of moisture in it is the lowest, which lie in the range of $15-25 \mathrm{~m}^{3} / \mathrm{h}$.

After determining the optimum parameters providing the highest yield of lactulose powder having the desired levels of quality, the studies of the organoleptic and physicochemical parameters have been conducted. The studies showed that the values of the investigated parameters of dry lactulose are within the normalized values and meet the requirements set by the regulatory documentation.

An analysis of the content of the toxic elements in the resulting product was also carried out. The results of the analysis allow to conclude that the content of the toxic elements in the obtained lactulose powder does not exceed the normalized values set by the regulatory documentation.

\section{REFERENCES}

1. Gavrilov, G.B., Development of probiotic microflora in the product with lactulose. Dairy Industry, 2006; 6: 61-62.

2. Gavrilov, B.G., \& Gavrilov, G.B., Study of the parameters of lactose isomerization. Process and Technology of Food Production, 2009; 2: 87-90.

3. State Standard of Russia GOST 51939-02 "Milk and milk products. Test method for lactulose" 2010; 11 .

4. Ostroumov, L.A., Methods for obtaining and using lactulose. Dairy Industry, 2006; 3: 52.

5. Riabtseva, S.A., Production and use of lactulose. Milk Processing, 2007; 8: 32-35.

6. Riabtseva, S.A., Lactulose technology. Moscow: DeLi print, 2003; 229.

7. Kharitonov V.D., Filatov, Yu.I., Kharitonov, D.V., Methods for producing dry lactulose. Dairy Industry, 2000; 4: 17-18.

8. Khramtsov, A.G., Innovative technologies of producing lactulose. Milk Processing, 2011; 7: 38-40.

9. Khramtsov, A.G., Evdokimov, I.A., \& Riabtseva, S.A., New directions in the development of functional foods. Collection of scientific works. Series "Food" (Stavropol: NCSTU), 2005; 8, 14-20.

10. Khramtsov, A.G., Modern ideas about the importance of lactose and its derivatives. Dairy Industry, 2007; 2: 52.

11. Jeffrey, G.A., Huang, D., \& Pfeffer, P.E., Crystal structure and n.m.r. analysis of lactulose trihydrate. Carbohydr. Res., 1992; 226: 29-42.

12. Chen, X., Zhai, X., Shi, J. et al., Lactulose mediates suppression of dextran sodium sulfateinduced colon inflammation by increasing hydrogen production. Digestive Diseases and Sciences, 2013; 58: 1560-1568.

13. Olano, A., Calvo, M., \& Corzo, V., Changes in the carbohydrate fraction of milk during heating processes. Food Chemistry, 1989; 31: 259-265.

14. Schumann, C., Medical, nutritional and technological properties of lactulose. Eur J Nutr., Suppl. 2002; 1: 17-25.

15. Altieri, C., Bevilacqua, A., Perricone, M. et al., Using a simplex centroid to study the effects of $\mathrm{pH}$, temperature and lactulose on the viability of Bifidobacterium animalis subsp. lactis in a model system. Anaerobe, 2013; 23: 23-26. 